Original Research Paper

\title{
Dissolution Sintering Technique to Create Porous Copper with Sodium Chloride Using Polyvinyl Alcohol Solution through Powder Metallurgy
}

\author{
Cynthia Waters, Stephen Ajinola and Mustafa Salih \\ Department of Mechanical Engineering, \\ North Carolina A\&T State University, Greensboro, NC, USA
}

\author{
Article history \\ Received: 22-02-2016 \\ Revised: $24-02-2016$ \\ Accepted: 26-02-2016 \\ Corresponding Author: \\ Cynthia Waters \\ Department of Mechanical \\ Engineering, North Carolina A\&T \\ State University, Greensboro, NC, \\ USA \\ Email:kwaters@ncat.edu
}

\begin{abstract}
The main purpose of this paper was to investigate the relative densities, porosities, compression strength and energy absorbed by porous copper $(\mathrm{Cu})$ formed via the dissolution sintering technique using Polyvinyl Alcohol (PVA) solution as a binder with Sodium Chloride $(\mathrm{NaCl})$ as space holder. Porous $\mathrm{Cu}$ was fabricated through powder metallurgy route using dissolution sintering technique by mixing $\mathrm{Cu}$ with $\mathrm{NaCl}$ in the volume ratio of 1:1, 1:2, 1:3 and 1:4 and adding PVA solution as binder. The mixture was poured into a press die of 1 inch internal diameter and a pressure of $375 \mathrm{MPa}$ was applied by a 4 column hydraulic press to create the green form. The $\mathrm{NaCl}$ was leached out in hot water at $70^{\circ} \mathrm{C}$ and then sintered to a temperature of $850^{\circ} \mathrm{C}$. Porosity values were determined from density measurements to give the porosity values of $42.2,44.87,45.71$ and $57.79 \%$ for volume ratio of $1: 1,1: 2,1: 3,1: 4$ respectively. Compression tests were also performed. The results of various plots were used in determining the energy absorbed per unit volume of value of $9.637 \mathrm{MJ} / \mathrm{m}^{3}, 0.750 \mathrm{MJ} / \mathrm{m}^{3}, 0.167 \mathrm{MJ} / \mathrm{m}^{3}, 0.109 \mathrm{MJ} / \mathrm{m}^{3}$ and the compressive strength of $40 \mathrm{MPa}, 3.75,0.72 \mathrm{MPa}, 0.26 \mathrm{MPa}$ for volume ratio of $1: 1,1: 2,1: 3$ and $1: 4$ respectively. Scanning Electron Microscope (SEM) was used to characterize the morphology of the pure $\mathrm{Cu}$, the $\mathrm{NaCl}$ and the resulting porous $\mathrm{Cu}$.
\end{abstract}

Keywords: Porous $\mathrm{Cu}$, Porosity, Energy-Absorbed, Compressive Strength, PVA

\section{Introduction}

Porous metal production has increased within the last two decades due to its use in many industrial, aerospace and biological applications because of the ability to control the porosities. One important property exhibited by porous metals are their strength to weight ratio which can also be exploited in an energy absorption and sound control system environment at minimum cost (Aly, 2007; Salimon et al., 2005) Most of the metal foams in the market are closed aluminum foam which are produced by semi liquid and liquid forming process (Aly, 2007; Salimon et al., 2005; Zhao et al., 2005). Various techniques have been used to produce porous metals and Powder Metallurgy (PM) method is one of them. The PM method involves the use of a space holder and examples include magnesium, sodium chloride $(\mathrm{NaCl})$ and carbamide (urea) etc. The space holder can be later removed by leaching out in hot water or by thermal removal (Sharma et al., 2011; Tuncer and Arslan, 2009). The choice of $\mathrm{NaCl}$ as space holder in this study was due to its semi-spherical shape which gives it more uniform macro pores. If there is an increase in porosities with an acicular pore shapes there is frequently a corresponding decrease in the strength of the foam (Tuncer and Arslan, 2009; Esen and Bor, 2011). Every material structure and method has its own merits and demerits and the dissolution sintering technique to create porous materials has a limitation of not being able to form porosities more than $70 \%$ and this is a particular disadvantage in aerospace where they desire a porous material with porosities of almost $90 \%$ 
(Sharma et al., 2011; Tuncer and Arslan, 2009; Esen and Bor, 2011; Ye and Dunand, 2010; Jiang et al., 2005; Alizadeh and Mirzaei-Aliabadi, 2012; Dunand, 2004; Bram et al., 2000; Smorygo et al., 2012; Parvanian and Panjepour, 2012).

This research reports that a Polyvinyl Alcohol solution (PVA) can be used as a binder in the preparation of porous $\mathrm{Cu}$ via dissolution techniques. It also reports the effective applied pressure required in creating stable green forms. Finally, porosities were determined from density measurements and the compressive strength and energy absorbed is obtained from the compression results.

\section{Materials and Methods}

\section{Raw Materials}

High purity commercial $\mathrm{Cu}$ powder (SM400105R with 99.7\% purity, purchased from Art mold). The powders were then screened using standard ASTM sieves to obtain particle sizes ranging from 40-75 microns. The $\mathrm{Cu}$ powder was then mixed with $\mathrm{NaCl}$ (kosher salt) of particle size ranging from 250-300 microns obtained from sieves.

\section{Composition Selection}

The composition of the $\mathrm{Cu}$ and $\mathrm{NaCl}$ are in the following volume ratio of $\mathrm{Cu}$ to $\mathrm{NaCl} ; 1: 1,1: 2,1: 3,1: 4$ respectively. The mass of the metal to be used in the batch mixture can be calculated using the equation below with their respective volume fractions:

$$
\begin{aligned}
& M_{A}=\frac{M_{T}}{\frac{\rho_{B}}{\rho_{A}}\left(\frac{1}{\vartheta_{A}}-1\right)+1} \\
& M_{A}+M_{B}=M_{T}
\end{aligned}
$$

Where:

$M_{A}=$ Mass of metal in grams

$M_{B}=$ Mass of space holder in grams

$M_{T}=$ Total mass of metal and space holder in grams

$\rho_{A}=$ Density of metal in $\mathrm{g} / \mathrm{cm}^{3}$

$\rho_{B}=$ Density of space holder in $\mathrm{g} / \mathrm{cm}^{3}$

$\vartheta_{A}=$ Volume fraction of the metal

\section{Binder Preparation}

A binder purchased from Sigma Aldrich $(1.5 \mathrm{~g}$ of PVA, MW 89000, 99+\% hydrolyzed) was mixed with $14.5 \mathrm{~mL}$ of water and heated to a temperature range of about $80-100^{\circ} \mathrm{C}$ in a closed container for $15 \mathrm{~min}$ to achieve complete dissolution of the PVA and then cooled to room temperature. The prepared PVA solution was added as a binder to give gluing properties to the mixture.

\section{Preparation of Batch and Compacting}

The batch compositions were thoroughly mixed with the aid of a $250 \mathrm{~mL}$ mortar and pestle for $5 \mathrm{~min}$ for complete homogenization. The sample was poured into a linch diameter press die and then compacted by the application of a uniaxial pressure of $375 \mathrm{MPa}$ using manual four-column hydraulic laboratory press with digital heated platens into cylindrical pellets of 1 inch diameter and 0.5 inch thickness.

\section{Dissolution}

The samples were subsequently dried in air for $1 \mathrm{~h}$ after which the $\mathrm{NaCl}$ was dissolved as follows; samples were placed in a tea sieve and suspended in a beaker containing ample water to immerse the sieve and heated for $2 \mathrm{~h}$ at $70^{\circ} \mathrm{C}$ on a hotplate with magnetic stirrer. The samples were then removed from the water after this first stage of the dissolution process and air dried.

\section{Sintering}

The third stage of the process involved placing the samples in a GSL-1700X high temperature vertical tube furnace which uses $\mathrm{MoSi}_{2}$ as heating elements with 4 inch diameter high purity alumina tube all purchased from MTI. The temperature was controlled by high precision controller with the accuracy $+/-1^{\circ} \mathrm{C}$. The chamber of the furnace was flushed with Argon gas and purged twice to remove all other gases present in the chamber after which vacuum was achieved using pump with maximum vacuum pressure. The temperature profile for the sintering process is shown in Fig. 1. The rate of sintering is dictated by both the thermal driving force and the mobility of the atoms which depends on sintering temperature. The temperature for the sintering is typically 0.8 times the Temperature of melting. The furnace was heated at the rate of $10^{\circ} \mathrm{C} / \mathrm{min}$ up to $200^{\circ} \mathrm{C}$ in order to evaporate the water and PVA completely and this was followed by heating it at $5^{\circ} \mathrm{C} / \mathrm{min}$ up to $850^{\circ} \mathrm{C}$ and holding at this temperature for $4 \mathrm{~h}$ then cooling it to room temperature at the rate of $10^{\circ} \mathrm{C} / \mathrm{min}$. The final stage of dissolution occurred after sintering when the samples were placed below running water for $15 \mathrm{~min}$ to ensure that the remaining space holder was removed and the sample was dried in the muffle furnace to temperature of $120^{\circ} \mathrm{C}$. The entire process is schematically shown in Fig. 2. Finally, a porous $\mathrm{Cu}$ disc was obtained as shown in Fig. 3. The surface of the porous sample was ground and polished to reveal the morphology of the samples. The fabrication flow process has also been shown and explained by Parvanian and Panjepour (2012). 


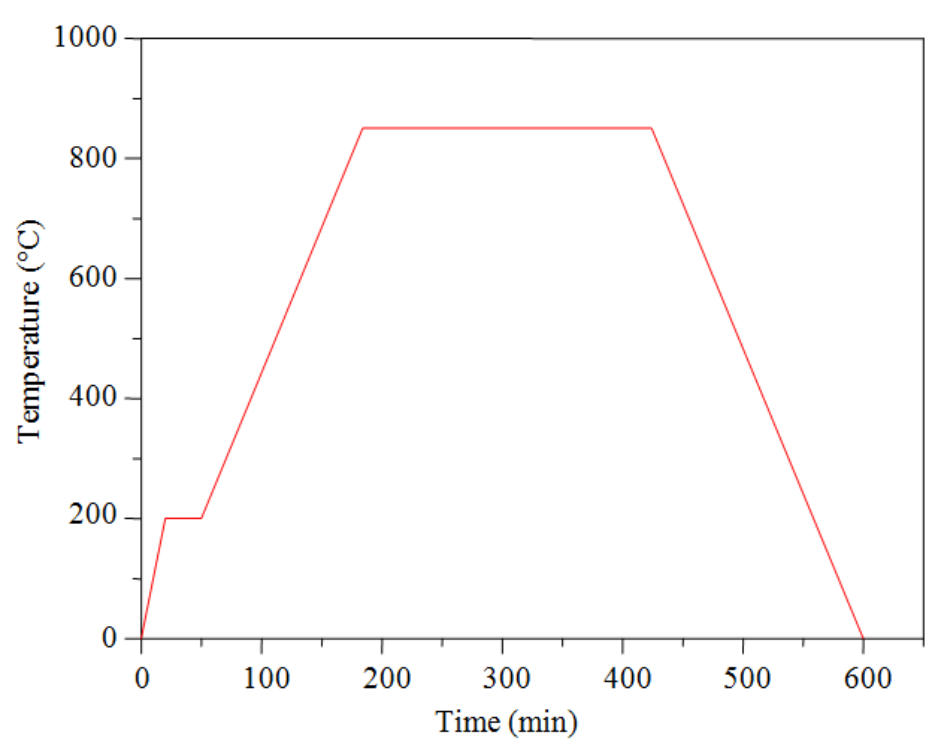

Fig. 1. Sintering time-temperature profile

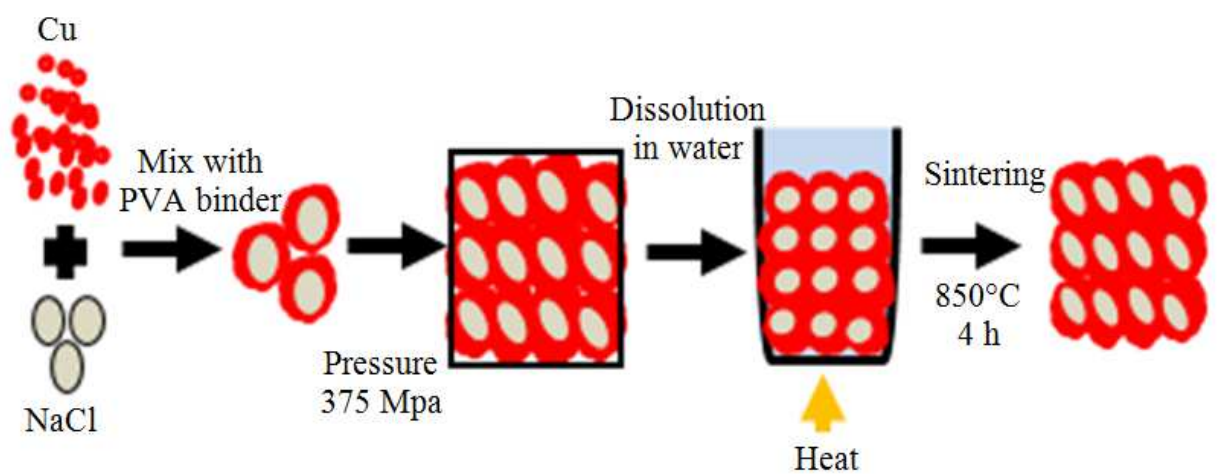

Fig. 2. Schematics diagram of the process of porous $\mathrm{Cu}$ fabrication

\section{Results}

\section{Characterization of Samples}

The discs shape of the porous coppers was examined in term of density, relative density, porosity, SEM analysis, compressive strength and energy absorbed. The morphology was examined by scanning electron microscope. The density was determined by Archimedes methods using Mettler Toledo kit. Compression tests were carried out using an Instron machine to determine compressive stress and strain behavior and then energy absorbed was computed from the plots.

\section{Image and SEM Characterization}

Figure 3 shows the pictorial view of the $\mathrm{Cu}$ disc mixed with $\mathrm{NaCl}$ in a volume ratio of 1:1 ratio. Pores created were relatively disperse and one notices that they are open cells and extend to the surface. The
SEM was used to show the morphology of the raw salt, pure $\mathrm{Cu}$ in Fig. $4 \mathrm{a}$ and $4 \mathrm{~b}$ respectively. The $\mathrm{Cu}$ powder was sieved to be between 40-75 microns. Figure 4 a presents the $\mathrm{Cu}$ to be semi-spherical and sizes are smaller than expected ranging from 5-50 microns. The $\mathrm{NaCl}$ particles are meant to be larger than the metal powder in order for the metal powders to fully coat the temporal spacer and allow the creation of pores. The SEM image confirms that the $\mathrm{NaCl}$ is an order of magnitude larger than the $\mathrm{Cu}$ powders. The morphology of porous samples with volume ratio of the $1: 1,1: 2,1: 3,1: 4$ respectively as it can be seen in Fig. 4c-f.

\section{Relative Density and Porosities}

The densities of the different volume ratios were determined using Mettler Toledo's density kits for a solid porous substance which is both analytical and precise. This process was carried out at temperature 
$22.6^{\circ} \mathrm{C}$ in ethanol which was specified as one of the auxiliary liquids that could be used for experiment. It involved using Archimedes' principle, which states that if body is immersed in a fluid its apparently loses its weight by an amount equal to the weight of the fluid it displaces. The results are shown in the Table 1 and the values show that the densities decrease as the amount of the space holder increases. The density results were obtained from the Mettler kit while the relative densities were computed from Equation 3:

$$
\text { R.D. }=\frac{\rho}{\rho_{s}}
$$

where, the dense $\mathrm{Cu}$ value is considered to be the theoretical density of solid $\mathrm{Cu}$ and:

$$
\begin{aligned}
& R \cdot D=\text { The ratio of the densities } \\
& \rho=\text { The density of the porous } \mathrm{Cu} \\
& \rho_{s}=\text { The density of the solid } \mathrm{Cu}
\end{aligned}
$$

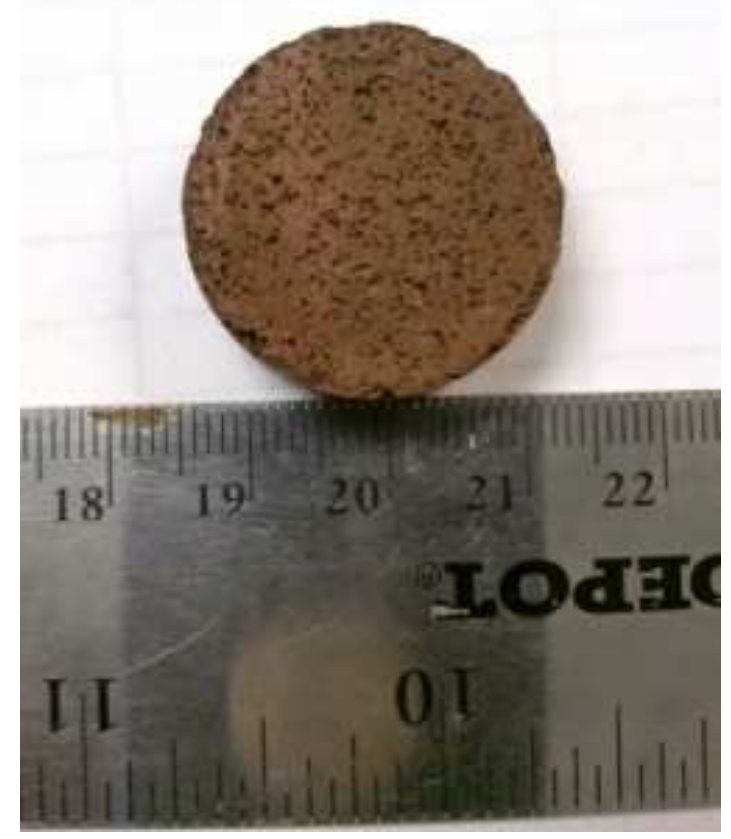

Fig. 3. Pictorial view of volume ratio of $\mathrm{Cu}$ : $\mathrm{NaCl}(1: 1)$

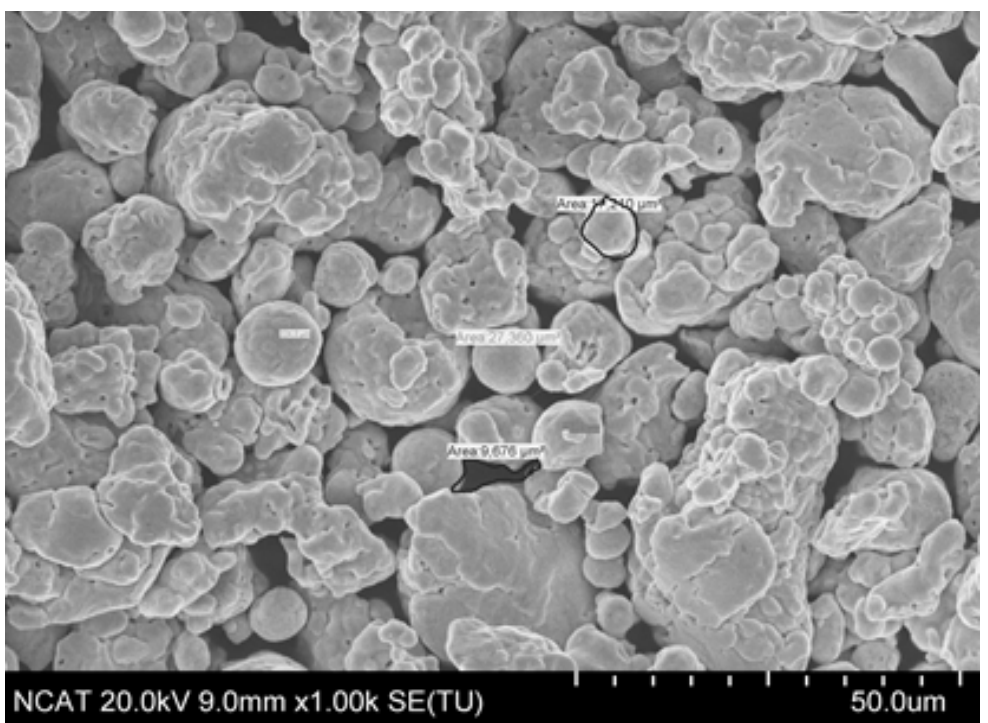

(a) 


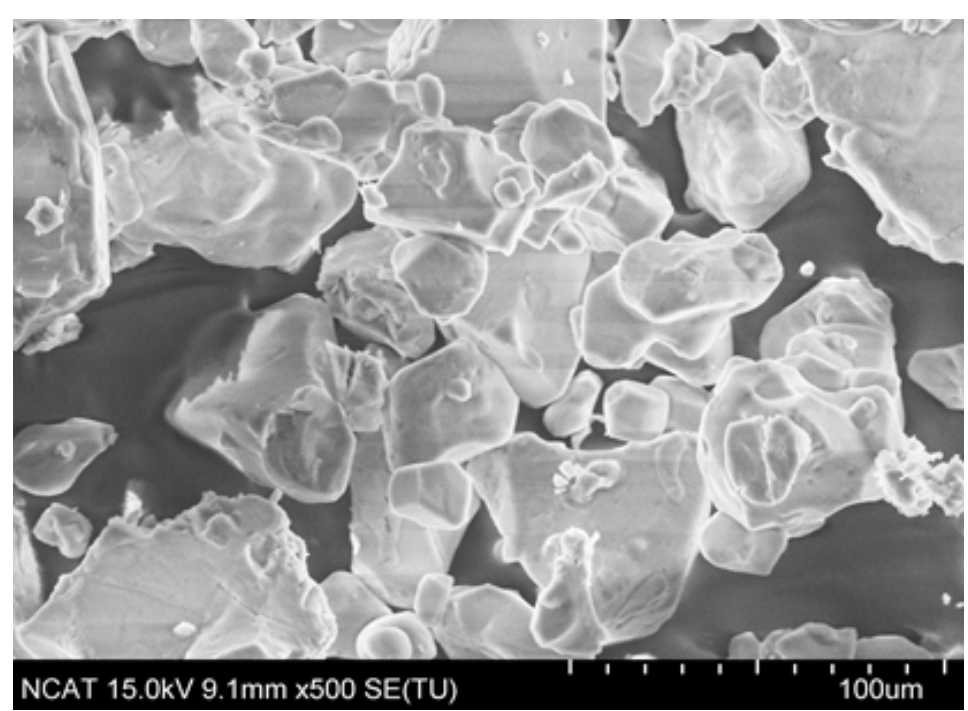

(b)

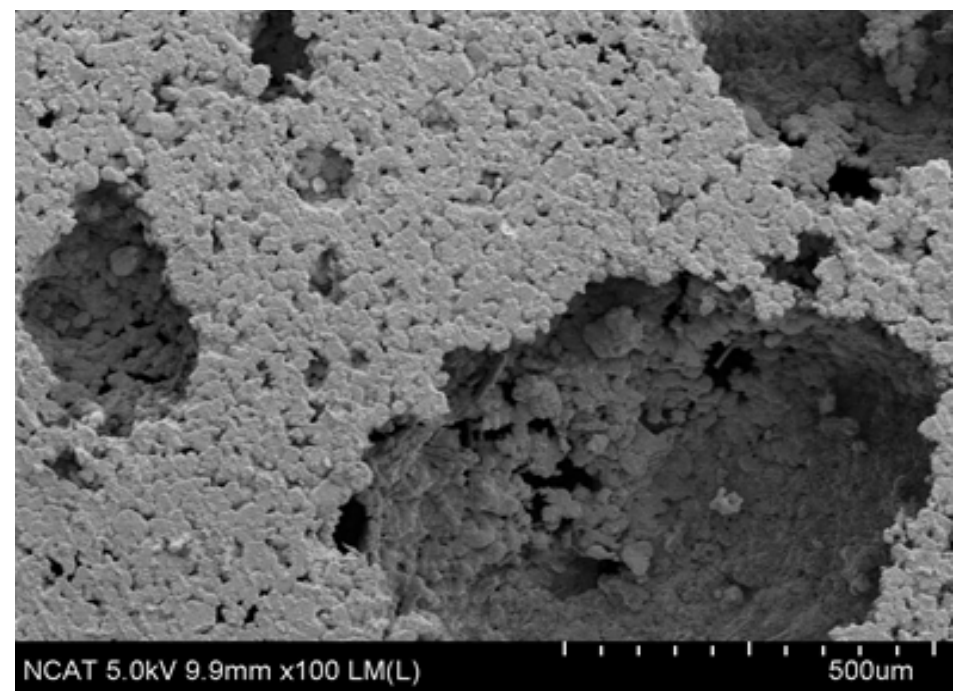

(c)

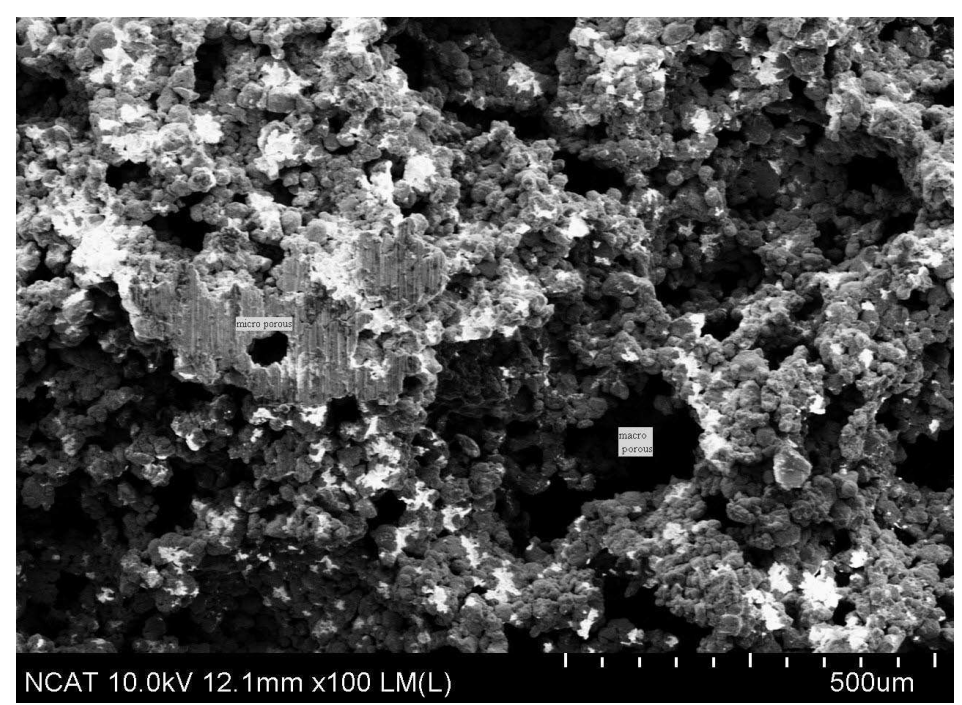

(d) 


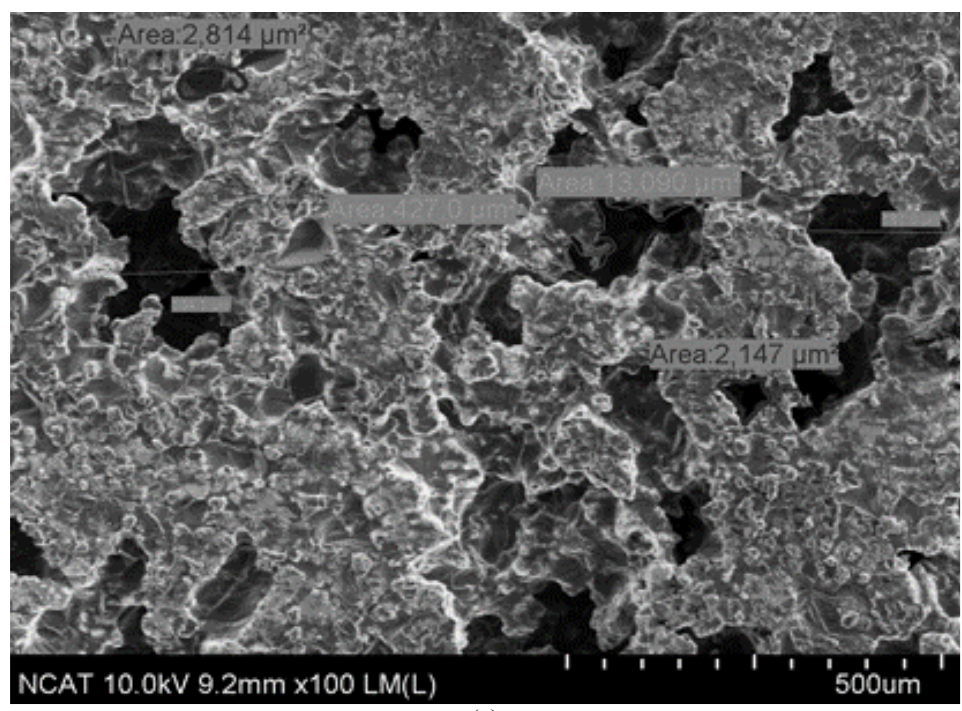

(e)

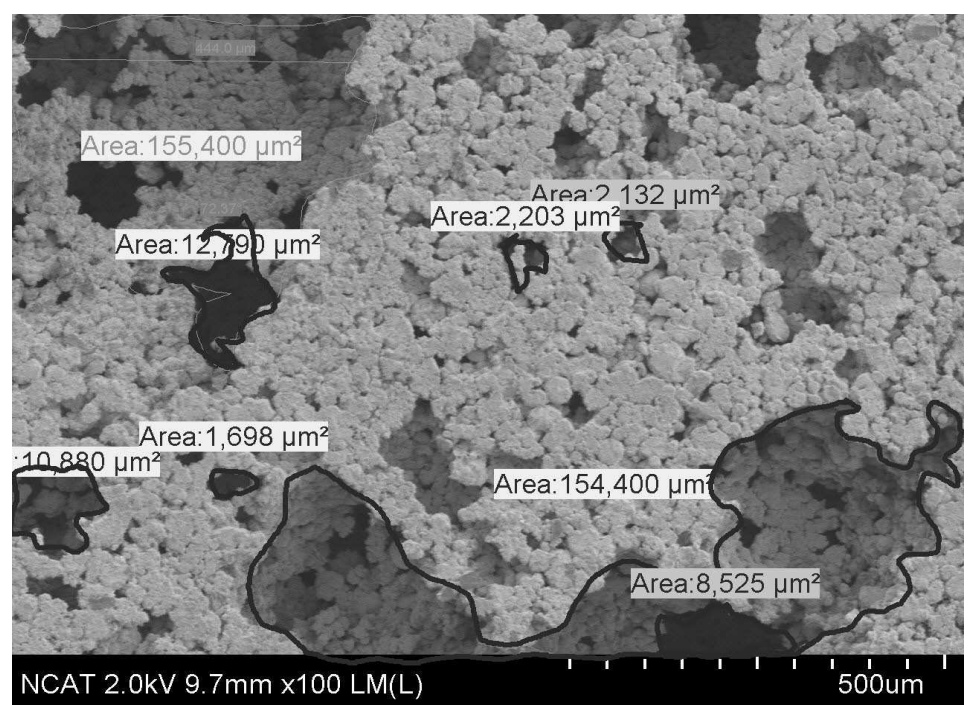

(f)

Fig. 4. (a) Pure $\mathrm{Cu}$ powder $\mathrm{Cu}$ : (b) Pure $\mathrm{NaCl}$ particles $\mathrm{NaCl}$, (c) $\mathrm{Cu}: \mathrm{NaCl}$ sintered in a (1:1) ratio. (d) $\mathrm{Cu}: \mathrm{NaCl}$ sintered in a (1:2) ratio. (e). $\mathrm{Cu}: \mathrm{NaCl}$ sintered in a (1:3) ratio (f) sintered in a (1:4) ratio

The results are shown in the Table 1.

The porosities are computed from the results of the densities obtained using the Equation 4. The porosities increase as the space holder ratio increases:

$$
\text { Porosity }=\left(1-\frac{\rho}{\rho_{s}}\right) \times 100
$$

It can be seen from Table 1 that the relative density of the samples decrease as the volume of the space holder added increases from a ratio of 1 to 4 , also the amount of the porosity is seen to have increased owing to the fact that there is an increase in the number of pores.

\section{Mechanical Characterization}

The Material Testing System (MTS) 810 Testing System was hosted by Center for Composite Materials Research (CCMR) of NCAT which was configured to meet different testing needs. The machine model has force capacity of $250 \mathrm{KN}$ axial forces which is over a displacement range of $+/-2.5$ inches and the displacement rate of $0.02 \mathrm{inch} / \mathrm{min}$ was used. The MTS Model 810 was used to determine the compressive strength and ASTM E9 was used. The compression platen device was designed to test 1 inch diameter by 0.5 inch long specimens. The resulting compressive stress and strain values in addition to the energy absorbed as computed from the stress strain curve up to the point of crushing are shown in Table 1. 
Three regions of a typical porous metal compressive test are: A linear elastic deformation stage, a plastic deformation and pore collapse stage and finally a densification stage as shown in Fig. 5 (Cady et al., 2009). We expect a similar behavior for the current samples. The compression plots are shown in Fig. 6 and 7 and their shapes are as expected from foam/porous metallic behavior which followed the trends by other research work. The stress-strain curves of porous $\mathrm{Cu}$ with different volume ratios showed the three distinct regions of deformation Fig. 6 displays only 3 volume ratios and Fig. 7 adds the curve for the pure $\mathrm{Cu}$ sample to provide a reference as to the decrease in compressive behavior.

Table 1. Density, relative density and porosities

\begin{tabular}{|c|c|c|c|c|}
\hline $\begin{array}{l}\text { Sample volume } \\
\text { ratio }(\mathrm{Cu}: \mathrm{NaCl})\end{array}$ & Density $\left(\mathrm{g} / \mathrm{cm}^{3}\right)$ & Relative density & Porosity (\%) & $\begin{array}{l}\text { Compressive } \\
\text { Strength (MPa) }\end{array}$ \\
\hline $\mathrm{Cu}+\mathrm{NaCl}(1: 1)$ & 5.177 & 0.578 & 42.22 & 40.00 \\
\hline $\mathrm{Cu}+\mathrm{NaCl}(1: 2)$ & 4.940 & 0.551 & 44.87 & 3.750 \\
\hline $\mathrm{Cu}+\mathrm{NaCl}(1: 3)$ & 4.864 & 0.543 & 45.71 & 0.720 \\
\hline $\mathrm{Cu}+\mathrm{NaCl}(1: 4)$ & 3.782 & 0.422 & 57.79 & 0.260 \\
\hline
\end{tabular}

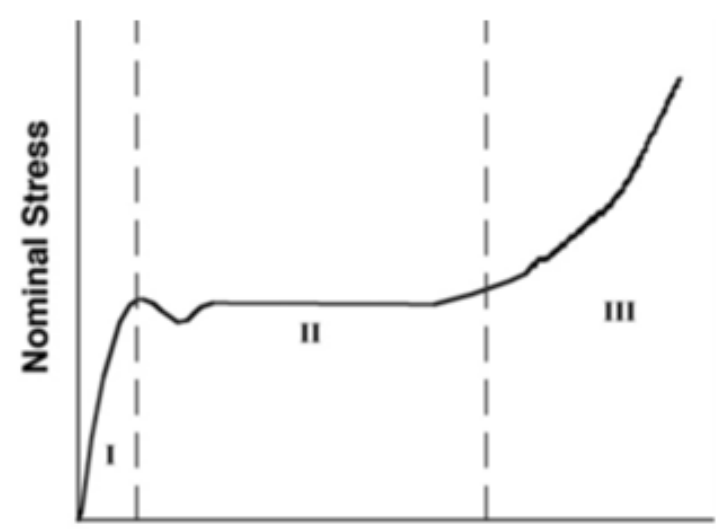

Nominal Strain

Fig. 5. Nominal stress-nominal strain curve (Cady et al., 2009)

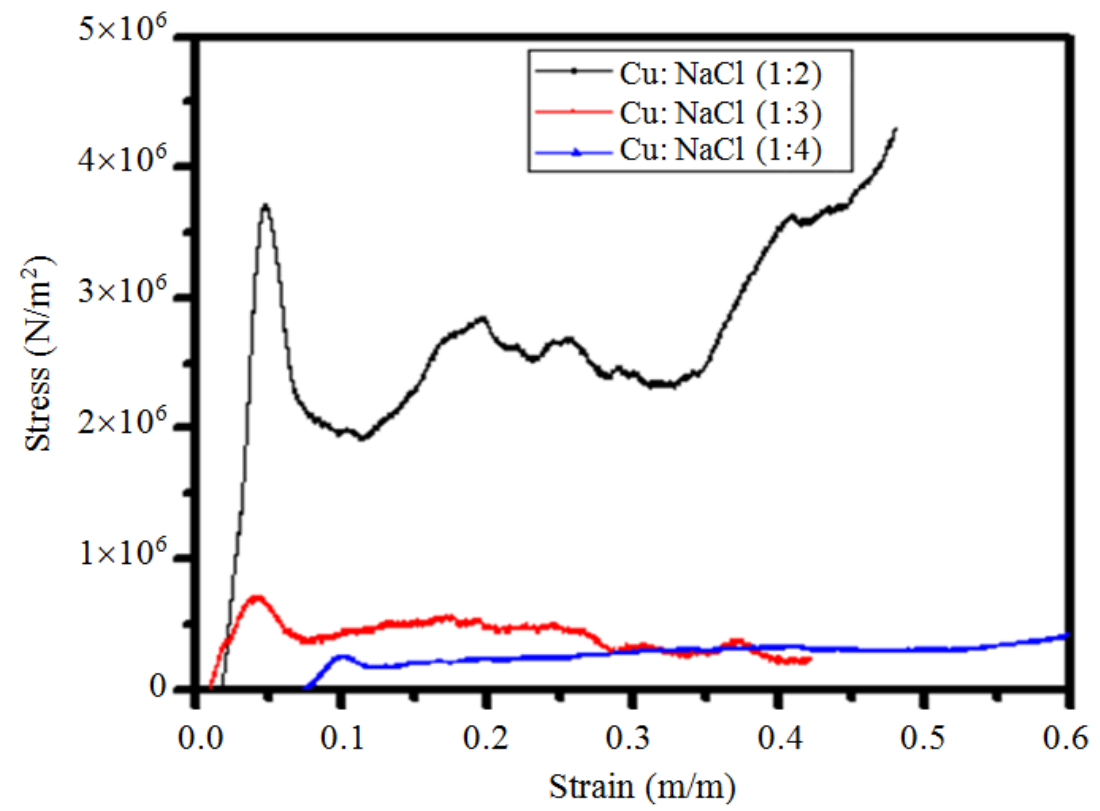

Fig. 6. Plot of stress Vs strain of volume ratio of 1:2, 1:3, 1:4 of $\mathrm{Cu}$ to $\mathrm{NaCl}$ 


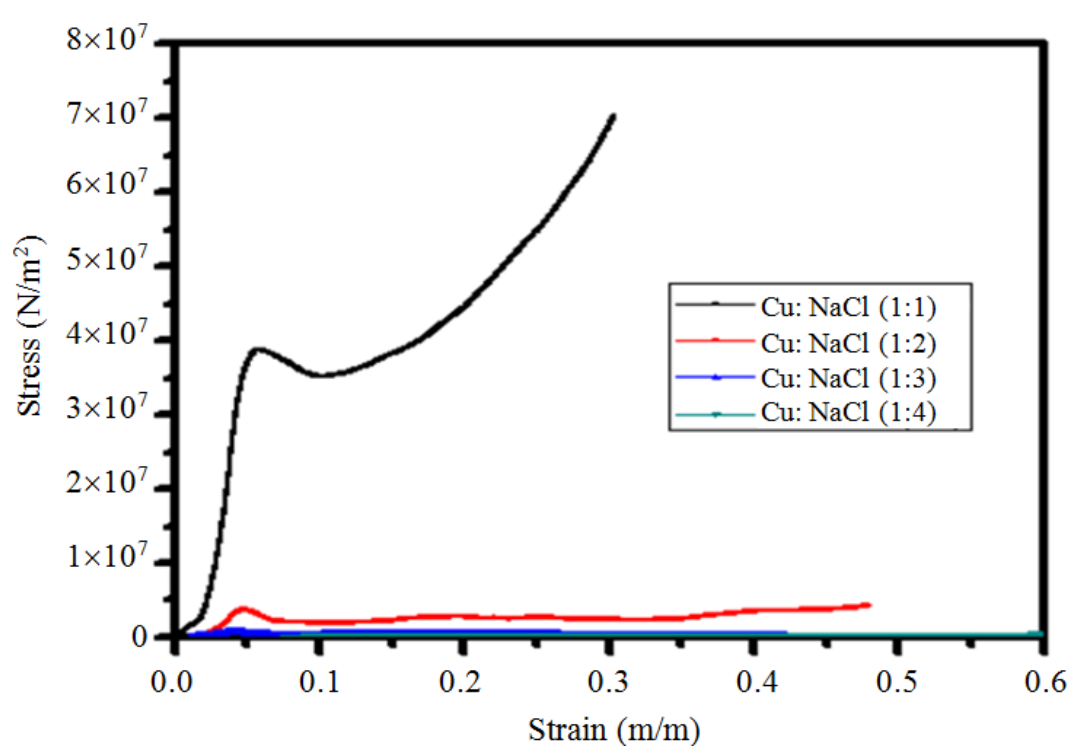

Fig. 7. Plot of stress Vs strain of volume ratio of $1: 1,1: 2,1: 3,1: 4$ of $\mathrm{Cu}$ to $\mathrm{NaCl}$

The energy absorbed per unit volume $\left(W_{b}\right)$ is taken to be area underneath the stress strain curve in the compression test and is expressed by equation:

$W_{b}=\int_{\varepsilon_{0}}^{\varepsilon_{1}} \sigma(\varepsilon) d \varepsilon$

Figure 6 and 7 gives the compression results of different volume ratios of the space holder. The reason why there is large observed compressive strength change from volume ratio $1: 1$ to $1: 2$ was due to a large porosities difference in $1: 1$ to $1: 2$. The difference between the porosity values in the $1: 2$ to $1: 3$ and $1: 4$ is small and this explains the minor change in the compressive strength. The compressive strengths are $40 \mathrm{MPa}, 3.75 \mathrm{MPa}, 0.72 \mathrm{MPa}$ and $0.26 \mathrm{MPa}$ for volume ratio of $1: 1,1: 2,1: 3$ and $1: 4$ respectively.

The energy absorbed in the test is found by integrating the regions of strain between 0.054 to 0.277 for volume ratio $1: 1$ and energy absorbed per unit volume was computed to be $9.637 \mathrm{MJ} / \mathrm{m}^{3}$ according to Equation 5. For the other volume ratios the results are as follows: Strain region of 0.048 to 0.355 , the energy absorbed per unit volume was $0.750 \mathrm{MJ} / \mathrm{m}^{3}$ for volume ratio of 1:2; the strain range of 0.010 to 0.416 and energy absorbed per unit volume was $0.167 \mathrm{MJ} / \mathrm{m}^{3}$ for volume $1: 3$, strain region for 0.079 to 0.497 and energy absorbed was $0.109 \mathrm{MJ} / \mathrm{m}^{3}$ for volume ratio of 1:4.

The next step in characterizing the results of porous copper as regards to its properties under mechanical loads, the relation between the relative modulus to relative density in term of power is shown in the Fig. 8 and 9 shows the relation between the relative compressive stresses to relative density.

\section{Discussion}

PVA solution was chosen as a binder in order to provide strength in the green form. We discovered that it did not have an adverse effect on $\mathrm{Cu}$ and $\mathrm{NaCl}$ behavior and therefore it can be successfully used as a binder for producing porous $\mathrm{Cu}$.

The compressive strength is the point at which the sample reaches the maximum stress point, as shown in Fig. 6 and 7 and the area of the curve up to that point is region one. After that point, ending region one, the pore collapse stage begins and consists of an initial load drop due to local buckling and failure of the wall structure on a plane normal to the loading direction at the weakest region of the sample. Stresses in the collapse plane will increase as the cell walls interact with one another until the load level reaches a maximum value where the next plane of failure will occur. Finally, the densification stage shows a rapid increase in the load carried by the sample (Cady et al., 2009). The compression plots of Fig. 6 and 7 for different volume ratios of the space holder show a large observed compressive strength change from volume ratio $1: 1$ to $1: 2$ and is understood to be due to a large porosities difference in $1: 1$ to $1: 2$. The difference between the porosity values in the $1: 2$ to $1: 3$ and $1: 4$ is small and this explains the minor change in the compressive strength.

The relation between the relative modulus to relative density in term of power is shown in the Fig. 8 and 9. shows the relation between the relative compressive stresses to relative density. Both are explained by Gibson and Ashby (Parvanian and Panjepour, 2012; Gibson and Ashby, 1997) with the model is given by Equation 6: 


$$
\frac{E}{E_{s}}=C\left(\frac{\rho}{\rho_{s}}\right)^{n}
$$

The $C$ and $\mathrm{n}$ are constants and the value of $\mathrm{C}=0.60$ and $n=10.635$, this is also shown in the Fig. 8 .

Also, the relation between the relative compressive stress to relative density in term of power is also shown by the below equation and the value is:

$$
\frac{\sigma}{\sigma_{s}}=C\left(\frac{\rho}{\rho_{s}}\right)^{n}
$$

The $\mathrm{C}$ and $\mathrm{n}$ are constants, $\mathrm{C}=2.5904$ and $\mathrm{n}=$ 8.3016, as it was explained in Fig. 9. The difference between the Gibson/Ash by model and the fitted equation is due to non-uniformity in the structure of the porous copper both at the exterior and interior walls, non-idealized condition of the experiment like nonuniformity in the size, morphology changes in the cell edges and the presence of flaws in the cell wall and the size distribution of pores. The technique can never give a completely uniform spherical shape of the space holders i.e., spherical the wall thickness cannot be uniformed and the value of $\mathrm{C}$ is expected the lie within the range of 0.1 4.0 for open cellular structure (Parvanian and Panjepour, 2012; Gibson and Ashby, 1997). The value of our C is within the expected range; slight variation may be due to the environmental effect on the experiment conducted. The $\mathrm{y}$ represents $\mathrm{E} / \mathrm{E}_{\mathrm{s}}$ and $\sigma / \sigma_{s}$ in the Fig. 8 and 9 respectively while $\mathrm{x}$ represents $\rho / \rho_{s}$ in the Fig. 8 and 9 . The plot of relative compressive strength as function of a relative density shown in the Fig. 9 also explains an increase in strength with an increase in relative density which is demonstrated by the Ashby-like chart behavior of metal foams.

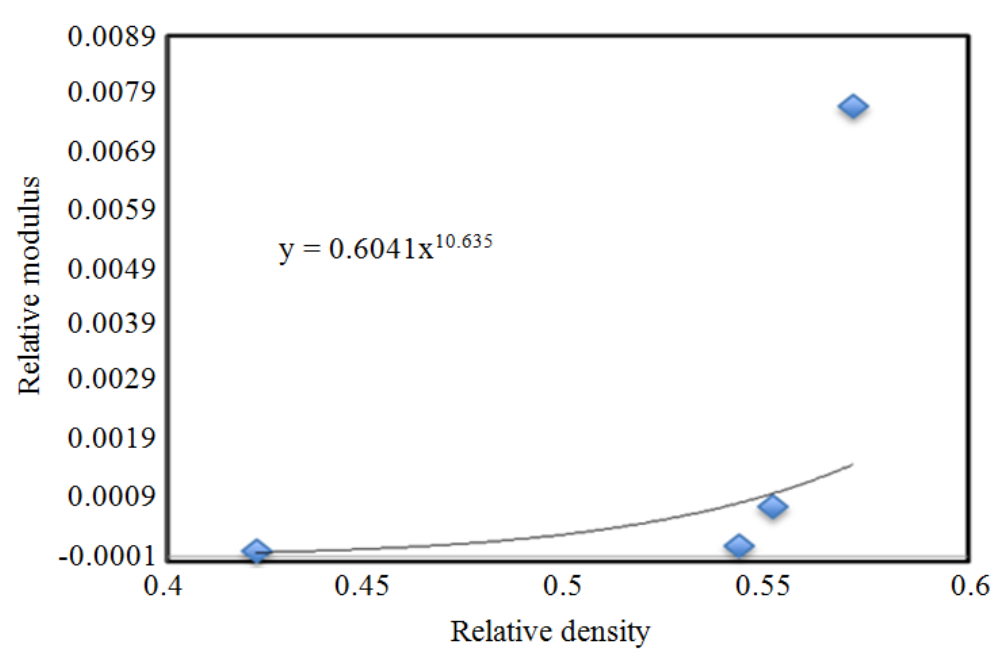

Fig. 8. Relative modulus versus relative density of porous copper

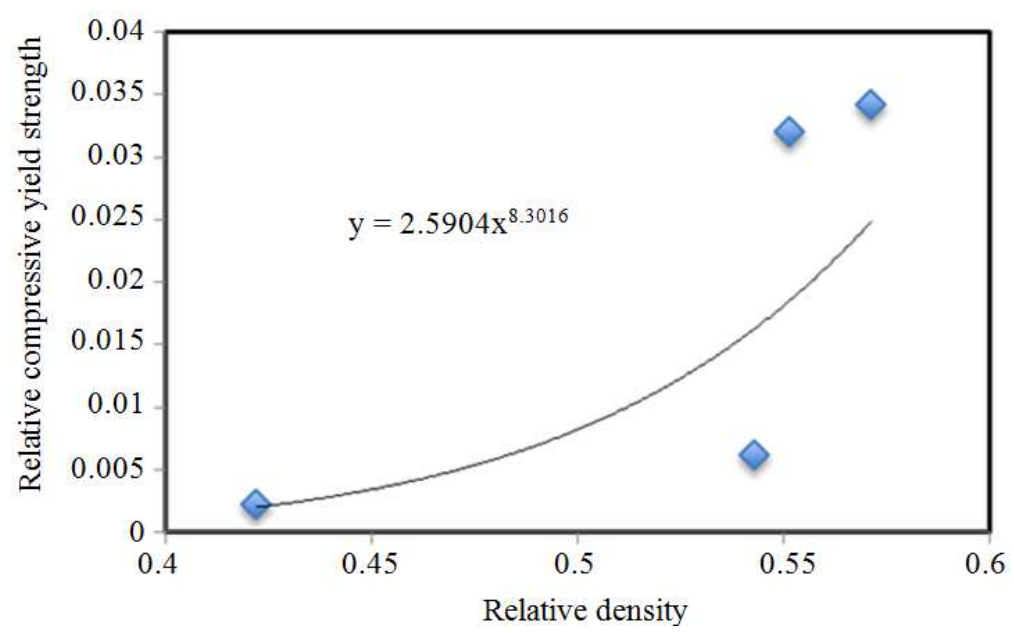

Fig. 9. Relative compressive yield strength versus relative density of porous copper 


\section{Conclusion}

Porous $\mathrm{Cu}$ was successfully fabricated by using $\mathrm{NaCl}$ as a space holder with the selection of one particle size range. PVA solution can be successfully used as a binder for producing porous $\mathrm{Cu}$. The porous $\mathrm{Cu}$ can be successfully sintered at temperature of $1123 \mathrm{~K}$ to give variable compressive strength. The morphology showed macro and micro pores in the SEM micrographs. We can conclude that it is possible to vary the compressive strength with a particular choice of space holder size by changing the volume fraction. Porosity is the key factor that affects the compressive strength of the porous sample. The mechanical deformation of our porous bodies occurs because of distortion in cell-wall regions and the cell wall thickness can influence the mechanical strength of these porous materials. We conclude that the energy absorbed decreases as the porosity increases. In other words, the strength scales with relative density. The power law function is exhibited by a plot of the relationship between the compressive strength and modulus to relative density as shown in Fig. 8 and 9.

\section{Acknowledgement}

We acknowledge the NSF ERC Center for Revolutionizing Metallic Biomaterials and the Center for Composite Materials Research Center both at NCAT, Dr. Sudher Nurella, John Skujins and Babatunde Adebiyi for their contributions to this research works.

\section{Author's Contributions}

Cynthia Waters: Participated in all experimental testing, data-analysis and contributed to the writing of the manuscript.

Stephen Ajinola: Participated in experimental plan and testing, data-analysis and contributed to the writing of the manuscript

Mustafa Salih: Participated in experimental plan, data-analysis and contributed to the writing of the manuscript.

\section{Ethics}

All rights reserved. No part of this publication maybe reproduced or transmitted in any form or by any means, electronic or mechanical, including photocopy, or any information storage and retrieval system, without permission in writing from the publisher or authors.

\section{References}

Alizadeh, M. and M. Mirzaei-Aliabadi, 2012. Compressive properties and energy absorption behavior of $\mathrm{Al}-\mathrm{Al}_{2} \mathrm{O}_{3}$ composite foam synthesized by space-holder technique. Mater. Design, 35: 419-424. DOI: 10.1016/j.matdes.2011.09.059

Aly, M.S., 2007. Behavior of closed cell aluminium foams upon compressive testing at elevated temperatures: Experimental results. Mater, Lett., 61: 3138-3141.

DOI: 10.1016/j.matlet.2006.11.046

Bram, M., C. Stiller, H.P. Buchkremer, D. Stöver and H. Baur, 2000. High-porosity titanium, stainless steel and superalloy parts. Adv. Eng. Mater., 2: 196-199.

DOI:

$10.1002 /(\mathrm{SICI}) 1527-$ 2648(200004)2:4<196::AID-ADEM196>3.0.CO;2-K

Cady, C.M., G.T. Gray III, C. Liu, M.L. Lovato and T. Mukai, 2009. Compressive properties of a closedcell aluminum foam as a function of strain rate and temperature. Mater. Sci. Eng.: A, 525: 1-6.

DOI: $10.1016 /$ j.msea.2009.07.007

Dunand, D.C., 2004. Processing of titanium foams. Adv. Eng. Mater., 6: 369-376. DOI: 10.1002/adem.200405576

Esen, Z. and Ş. Bor, 2011. Characterization of Ti-6Al$4 \mathrm{~V}$ alloy foams synthesized by space holder technique. Mater. Sci. Eng.: A, 528: 3200-3209. DOI: 10.1016/j.msea.2011.01.008

Gibson, L.J. and M.F. Ashby, 1997. Cellular Solids: Structure and Properties. 1st Edn., Cambridge University Press, Cambridge, ISBN-10: 0521495601, pp: 528.

Jiang, B., N.Q. Zhao, C.S. Shi, X.W. Du and J.J. Li et al., 2005. A novel method for making open cell aluminum foams by powder sintering process. Mater. Lett., 59: 3333-3336.

DOI: $10.1016 /$ j.matlet.2005.05.068

Parvanian, A. and M. Panjepour, 2012. Mechanical behavior improvement of open-pore copper foams synthesized through space holder technique. Mater. Design, 49: 834-841.

DOI: $10.1016 /$ j.matdes.2013.01.077

Salimon, A., Y. Bréchet, M.F. Ashby and A.L. Greer, 2005. Potential applications for steel and titanium metal foams. J. Mater. Sci., 40: 5793-5799. DOI: $10.1007 / \mathrm{s} 10853-005-4993-\mathrm{x}$

Sharma, M., G.K. Gupta, O.P. Modi, B.K. Prasad and A.K. Gupta, 2011. Titanium foam through powder metallurgy route using acicular urea particles as space holder. Mater. Lett., 65: 3199-3201.

DOI: 10.1016/j.matlet.2011.07.004 
Smorygo, O., A. Marukovich, V. Mikutski, A.A. Gokhale and G.J. Reddy et al., 2012. High-porosity titanium foams by powder coated space holder compaction method. Mater. Lett., 83: 17-19. DOI: 10.1016/j.matlet.2012.05.082

Tuncer, N. and G. Arslan, 2009. Designing compressive properties of titanium foams. J. Mater. Sci., 44: 1477-1484. DOI: $10.1007 / \mathrm{s} 10853-008-3167-\mathrm{z}$
Ye, B. and D.C. Dunand, 2010. Titanium foams produced by solid-state replication of $\mathrm{NaCl}$ powders. Mater. Sci. Eng.: A, 528: 691-697. DOI: 10.1016/j.msea.2010.09.054

Zhao, Y., T. Fung, L.P. Zhang and F.L. Zhang, 2005. Lost carbonate sintering process for manufacturing metal foams. Scripta Mater., 52: 295-298. DOI: $10.1016 /$ j.scriptamat.2004.10.012 